\title{
PUBLIC PERCEPTION TOWARDS THE MYTH OF CONSTITUTIONAL STATUS OF GILGIT BALTISTAN
}

\author{
Najaf Ali ${ }^{1}$, Mian Muhammad Azhar ${ }^{2 *}$, Shakil Akhtar ${ }^{3}$, Sarfraz Batool $^{4}$, Sidra Akram ${ }^{5}$ \\ ${ }^{1,5}$ Ph.D., Research Scholar, Department of Political Science \& IR, Government College University, Faisalabad, Pakistan; \\ $2^{*}$ Assistant Professor, Department of Political Science \& IR, Government College University, Faisalabad, Pakistan; \\ ${ }^{3,4}$ Assistant Professor, Department of Political Science, The Islamia University of Bahawalpur, Pakistan. \\ Email: *muhammad.azhar@gcuf.edu.pk
}

\section{Article History: Received on $19^{\text {th }}$ April 2021, Revised on $30^{\text {th }}$ May 2021, Published on $5^{\text {th }}$ June 2021}

\begin{abstract}
Purpose: The key purpose of this study is to answer the questions about the primary hurdles in determining and delaying the constitutional status, as well as ambiguities, reservations, demands, and desires among the youth of Gilgit Baltistan (GB).

Method: Primary as well as secondary sources, are used to answer the research questions. Questionnaire surveys and focus group discussions are used to collect the primary data, and the secondary data is collected from different published sources. The number of respondents was One Hundred Ninety and conducted three focus group discussions. All analyses were performed by using the latest version of SPSS.

Main Findings: This study finds out that the primary hurdle in determining and delaying the constitutional status of Gilgit Baltistan is its historical facts, Kashmir dispute, leadership crisis in GB, undesirable role of Kashmiri leader, and the non-serious behavior of Islamabad and its institution. Furthermore, undefined constitutional status creates uncertainty, ambiguity, sub-nationalism, and fear among youth.
\end{abstract}

Application of the study: The result will provide a guideline in policy-making regarding Gilgit Baltistan, and it provides a new direction for new researchers.

The originality of the study: The research identifies the primary hurdles in determining and delaying the constitutional status of GB as well as explores the demands and desires of the youth of GB. The study provides advanced knowledge in the current literature because this study finds out the desire of youth, particularly university students, based on first-hand knowledge collected from the respondents through the survey.

Keywords: Constitutional Status, Geostrategic Importance, Political Status, Public Perception, Geopolitics CPEC.

\section{INTRODUCTION}

In the northeast of Pakistan, the region of Gilgit Baltistan (GB) is located, and it shares a border with Xinjiang China, Ladakh (region of IOK) India, Wakhan corridor (Afghanistan), AJK, and KPK. The region's political status is ambiguous due to its association with the Kashmir dispute between India and Pakistan. The Maharaja of Kashmir ruled the region by annexing it in his princely state of Jammu and Kashmir in the 1940s, and the total area of the region is 27188 square miles (Shafique \& Iftikhar, 2017). The political history of GB has a fascinating domain because their political system is linked with Tibet's history. But after the treaty of Amritsar of 1846, the region was annexed in the state of Jammu and Kashmir (Bangash, 2010). Before the colonial era, there were many princely states under monarchies, and also there were several different tribes, civilizations, and dynasties (Khan, 2015). The local's revolt against the government of Maharaja Harisingh when the issue of state accession becomes in 1947. Brigadier Ghansara Singh (governor of Maharaja) was arrested on October 31, and Gilgit became independent on November 01,1947 (Jabeen \& Bukhari, 2020). The liberation forces (GB Scouts) were divides into three groups, Tiger forces, Eskimo force, and Ibex force. Raja Shah Rais Khan was the president of the provisional government. Gilgit stayed independent for 16 days from November 01, 1947, to November 16, 1947. Then Gilgit acceded themselves with Pakistan(Bouzas, 2017). While Baltistan region became independent on August 14, 1948, after several clashes and revolts (Kreutzmann, 2015).

Sardar Alam Khan was the first Pakistani official who landed at Gilgit Airport on November 16, 1947, as a political agent. In 1947, Karachi imposed Frontier Crimes Regulation (FCR) to administer the north region. Under the Karachi agreement of 1949, the government of Azad Jammu and Kashmir (AJK) handover the control of the region to Islamabad but no signatories from GB was there (Lambah, 2016). In 1964 Baltistan region became a full fledge agency, and a separate political agent was appointed there. Later in 1967, the post of resident for National Assembly was introduced, and Gilgit became headquartered. Under FCR, all powers were combined with the resident, like administration, high court, and commissioner revenues (Zain, 2010).

The Northern Areas Advisory Council (NAAC) was established in 1970 with a capacity of 16 members, and it was the major political development in the history of GB. The journey of FCR in GB was ended in 1974 as the result of the then Prime Minister Zulfiqar Ali Bhutto's reforms. The two agencies of GB (Gilgit and Baltistan) converted into five administrative districts. During Zia's martial law era, the entire region of Gilgit Baltistan was named Martial Law ZoneE. Later in the $1980 \mathrm{~s}$, an advisor to the prime minister for Northern Areas was introduced to resolve the problems, but that was not enough in the context of political status (Sokefeld, 2014). 
In 1994, the Benazir Bhutto government introduced the Legal Framework Order (LFO), and Northern Areas' rules of business were formed (Sering, 2010). Under the LFO seat of the chairmen and vice chairman was announced but later changed into chief executive and deputy chief executive. In 1999, the Northern Areas Executive Council (NAEC) was formed, and the council was comprised of 24 elected members. However, the federal minister of Kashmir Affairs and Northern Areas was to act as the Chief Executive of the council while the deputy chief executive was elected from the council member instead of nomination (Lambah, 2016). Later in the Musharraf era, the NAEC has re-titled as the Northern Areas Legislative Assembly (NALA), and a new assembly was proposed. The administrative and financial power of the federal ministry of Kashmir Affairs was transferred to the northern area's government. In 2007, the LFO 1994, amended as the Northern Areas Governance Order 2007.

However, in 2009, under Pakistan People's Party government, the "Gilgit Baltistan Empowerment and Self-governance Order 2009" passed. The name of Northern Areas of Pakistan changed into Gilgit Baltistan and administrative, judicial financial, and political reforms endorsed (Feyyaz, 2019). The "Gilgit Baltistan Empowerment and Self-governance Order 2009" allowed GB to form their provincial government, and the 24 members of the assembly were directly elected. There are six reserved seats for women and 3 seats for technocrats (Hussain, 2009). GB has immense importance owing to its geostrategic importance, but China Pakistan Economic Corridor (CPEC) massively enhanced its significance for Islamabad and Beijing as well as global powers too (Shamsi et al., 2019).

Since affiliation, Islamabad never showed GB as a part of its territory on its political maps and constitution. While after more than one year of abolishing articles 35A and 370 of the Indian constitution that left the special status from Indian Occupied Kashmir (IOK), Pakistan showed GB and Kashmir in one territory with a green line in her political map. The map clearly shows Siachen Glacier as a part of Pakistan (Reportar, 2020). The federal ministers of the Pakistan Tehrek e Insaaf (PTI) government used the issue of constitutional status as a political slogan during the Gilgit Baltistan Legislative Assembly (GBLA) election campaign in November 2020. Ali Amin Gandapure (Minister of Kashmir Affairs and GB), Zulfi Bukhari (Special assistant to PM), Murad Saeed (Minister for communication and postal services), and Firdous Ashiq Awan openly promised in public gatherings and election campaign rallies that "if PTI won the GBLA election 2020 then their party will resolve the issue of constitutional status". Pakistan People's Party and Pakistan Muslim League Nawaz also promised to resolve the issue. Though the ruling party PTI won the GBLA election still there is no such voice in the National Assembly of Pakistan regarding the constitutional status of GB (Tanvir, 2020).

The GBLA unanimously passed a bill on November 03, 2021, in its third session, regarding the constitutional status of Gilgit Baltistan. According to the bill, they demanded constitutional status and full recognition, and interim provincial status with membership in the upper and lower house. However, still today, GB is neither a constitutional part of Pakistan nor has representation in the Upper and Lower house (Nagri, 2021).

\section{Objectives of the Study}

The primary objective of this study is to find out the primary hurdles in determining and delaying the constitutional status of Gilgit Baltistan, which remain in limbo since the partition of the subcontinent. Moreover, the research is conducted to find out the views of youth, particularly university students, about the constitutional status of Gilgit Baltistan. Furthermore, the study explores the possible solution and suggestion to resolve the issue of constitutional status.

\section{LITERATURE REVIEW}

Though there are huge research works about GB's political rights and status, and some literature coded as; Feyyaz (2019)says that the region of Gilgit Baltistan has a unique identity due to her constitutional limbo and multicultural society. He further concluded that the core problem of GB is its CS. Joshi (2019) stated that the ruling of the Supreme Court of Pakistan in January 2019 declared Gilgit Baltistan as a part of the Kashmir issue and till the plebiscite in the region, GB remains disputed territory. Flowerday (2019) articulated that people who reside in territory belong to no nation-state. The main hurdle that creates fear among the people of GB is its constitutional status. Howe and Hunzai $\underline{(2019)}$ articulated that there was no representative from Gilgit Baltistan in the core committee of 'CPEC' due to their inbetween status, and GB cannot gain proper benefits from the mega project.

Holden (2019) assumed that two authorized documents, the Al-Jihad Supreme Court ruling (1999) and the "GB empowerment and self-governor order 2009," have certified the undefined status of GB. He also said that peoples are losing their hope about constitutional status day by day. Hussain and Javaid (2018) articulated that the undefined political status of GB is the major threat to Islamabad's interest because unclear political status created a sense of scarceness among Gbians. Bansal (2018) articulated in his book "Gilgit Baltistan and its saga of unending human rights violation" that the region is facing cynicism and human rights issues due to the unclear status of Gilgit Baltistan. Khan (2017) concluded that the relationship between GB and Pakistan is like the relationship between head and body. He also expressed that constitutional limbo creating human security fears among peoples of GB.

Dad (2016) expressed in his research that due to the absence of constitutional status, a vacuum-formed in GB was gradually filled by sectarian forces, nationalist sentiments, ethnic movements, and regional organizations. These forces reject the official stance of Kashmiri nationalism, and they want to introduce their recognition. Kreutzmann, (2015) 
concluded in his research that the region of Gilgit Baltistan had its history traced centuries back, but now the region faces several issues without clear status. In another study, Saini and Dar (2013) said that the status of Gilgit Baltistan is still undecided, neither a legal part of Pakistan nor the part of Jammu and Kashmir. GB has no recognition, no representation in the Upper and Lower House, and has no constitutional status. They further said that GB is a part of the disputed territory of J\&K but not part of Azad Jammu Kashmir. Hunzai (2013) concluded that due to the ambiguous status, the peoples of GB are under depression due to the demographic changes and several emerging issues in the region. Singh (2013) said that Gilgit Baltistan is neither a constitutional unit nor a province of Pakistan; consequently, they have no constitutional right.

Hong (2012) termed the status of GB as in-between status, and he argues the Empowerment Act 2009 was only a tactic to reduce emerging nationalist sentiment and Chinese trade influence. Bouzas (2012) concluded about the status of Gilgit Baltistan "neither full Pakistani nor identifying themselves with Kashmiri nationalism." He also wrote that the people of GB are facing a deficiency of the sense of belonging owing to their ambiguous CS. The researcher also specified that the "GB Empowerment and Self Governance Order 2009" is no more than a ruling approved by Islamabad without the consensus of inhabitants of GB. Shekhawat (2011) said that Islamabad used the sectarian issue as a divide and rule formula to govern GB without giving their due rights. Zain (2010) articulated that the only empowerment act is not enough to fulfill the GB's deficiency in the political arena of the federal government. They need a constitutional setup as well as full of fledging legislative power.

All the existing literature covers Gilgit Baltistan's history, issues, tourism, flora and fauna, and cultural aspects in different ways. The existing literature provides vast information about the myth of the constitutional status, but there is a huge research gap between all researchers, historians, and writers because they do not give significant importance to the youth, especially students. The study was conducted to fill up the research gap and tried to answer the below research questions. The manuscript also tried to minimize the deficiency in the literature about the constitutional status of GB.

\section{Research Questions}

1. What are the primary hurdles in determining and delaying the constitutional status of Gilgit Baltistan?

2. How the ambiguous constitutional status creates fear and ambiguity among the youth in Gilgit Baltistan?

3. What is the demand and desire of residents of GB, particularly youth, regarding the constitutional status?

\section{RESEARCH METHODOLOGY}

To explore and express the public perceptions towards the myth of CSGB participatory research approach was adopted. The universe of this study was the entire Gilgit Baltistan. GB covers 72,496 Square kilometers of area, and its population was 1.7 million in the 2017 census (Khan, 2017a). For sampling purposes, the cluster-sampling method used, and a nonprobability quota sampling approach is adopted. The main ambition of the study is to answer the research questions, and for accurate data collection, both primary and secondary sources are used. In primary data, qualitative and quantitative, both approaches are used. The quantity method is applicable when the study area and research problem concern wider society (Best, 2014). The area of this research is wider because it is associated with the entire Gilgit Baltistan. Therefore, the quantitative method for the collection, analysis, and interpretation of data was adopted.

Before starting the quantitative data collection, a comprehensive close-ended questionnaire was designed, and a pilot survey was conducted to test the validity of the questionnaire. Twenty questionnaires were distributed among Master, M.Phil. and Ph.D. students from GB studying in Faisalabad, and the respondents were requested to give brief feedback. Some valuable feedback and suggestions were received to make questions brief, short and concise. The questionnaire was finalized, reviewed by an expert, and SPSS software was used to test the reliability of the questionnaire.

The sampling size for the questionnaire survey was 190, and respondents are students from Gilgit Baltistan studying in different universities of the mainland. Fifteen close-ended questions cover the whole area of the research problem, and each question had four options. The ratio of female respondents was 1:4 (female: male). Then the close-ended questionnaire was distributed among the targeted population (University students) to identify the people's perceptions about the undetermined CSGB.

The qualitative data were collected by conducting Focus Group Discussion (FGD), and the FGD was used as an independent method to investigate the underline perception. FGD is used to explore common views (Dilshad \& Latif, 2013). Before the FGD, participants were informed about the domain of research as well as the venue was decided. The participants were university students and graduate belongs to GB between the ages of 18 to 30 . The participants were selected randomly, but representation from all districts of Gilgit Baltistan was ensured.

Furthermore, three focused group discussions were conducted, and the participants of FGD were university students, graduates, Master and Ph.D. scholars belong to Gilgit Baltistan. During FGD, chances were given to every participant to share their views. The participants of the first FGD were only undergraduate university students, the second FGD was conducted with the Master and Ph.D. students, and in the third FGD, participants were undergraduate, graduate, master, and Ph.D. students. 
The data collected from the field through a questionnaire is analyzed by using the latest version of SPSS. All figures and tables are drawn based on taken data through a questionnaire survey, and the FGD was interpreted based on the conclusion. However, the figures and graphs are elaborated in simple words to ensure every reader and researcher understandable.

Secondary data were collected from books, research articles published in journals, newspapers, and online internet sources. In this study, both primary and secondary data types were collected to answer the research questions with more accurate and latest data regarding the constitutional status. The validity of the whole research is directly proportional to the data collection method (Nayak \& Singh, 2015).

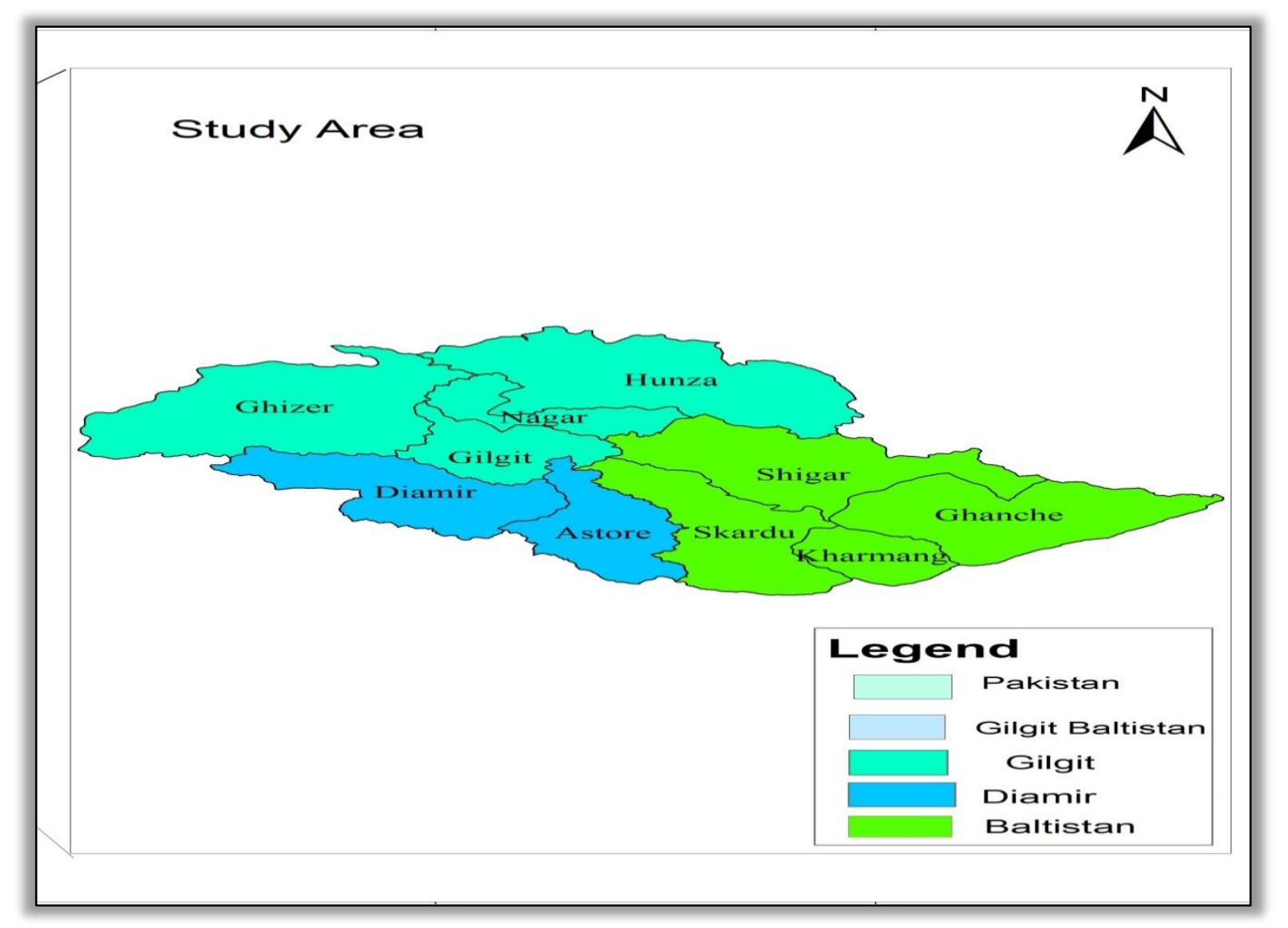

Figure 1: Map (The region of Gilgit Baltistan)

Source: Google

\section{RESULTS}

The result portion of the research showed the relationship among data and found the answer to the research questions around which the whole study is revolving (Pandey \& Pandey, 2015). The analysis of the obtained data from respondents through a questionnaire survey and FGD will show the public perceptions towards the myth of CSGB. As shown in the above map, the region of Gilgit Baltistan is divided into three divisions for an administrative purpose; Gilgit, Baltistan, and Diamer. Gilgit division is further divided into four districts (Gilgit, Ghizer, Hunza, and Nagar), and Baltistan also divides into four districts (Skardu, Ghanche, Shigar, and Kharmang) while the Diamer division is divided into 2 districts (Diamer and Astore) as Ali, (2019) articulated in her study.

\section{Association of GB with Kashmir dispute}

The below figure shows that the majority of the respondents i.e., 69.5 percent among 190 respondents were agreed with the statement that GB is associated with Kashmir, but only 22.6 percent respondent were not agreed with the statement while 7.4 percent of the respondent answer was uncertain and only .5 percent answer was none of these. In Focus Group Discussion (FGD), most participants have a negative opinion about the association of GB with Kashmir. They argued that GB got independence from Kashmiri Raja's government on November 01, 1947, and we are not part of Kashmir. Another participant said that GB is not a part of Kashmir but part of the Kashmir dispute, as (Naseem, 2007) articulated in his book. Further participants in FGD were not wanted to call them Kashmiri, and they argued that GB has its history, culture, language, and ethnicity, as (Dad, 2016) says in his finding. The below figure shows the accurate analysis of data. 


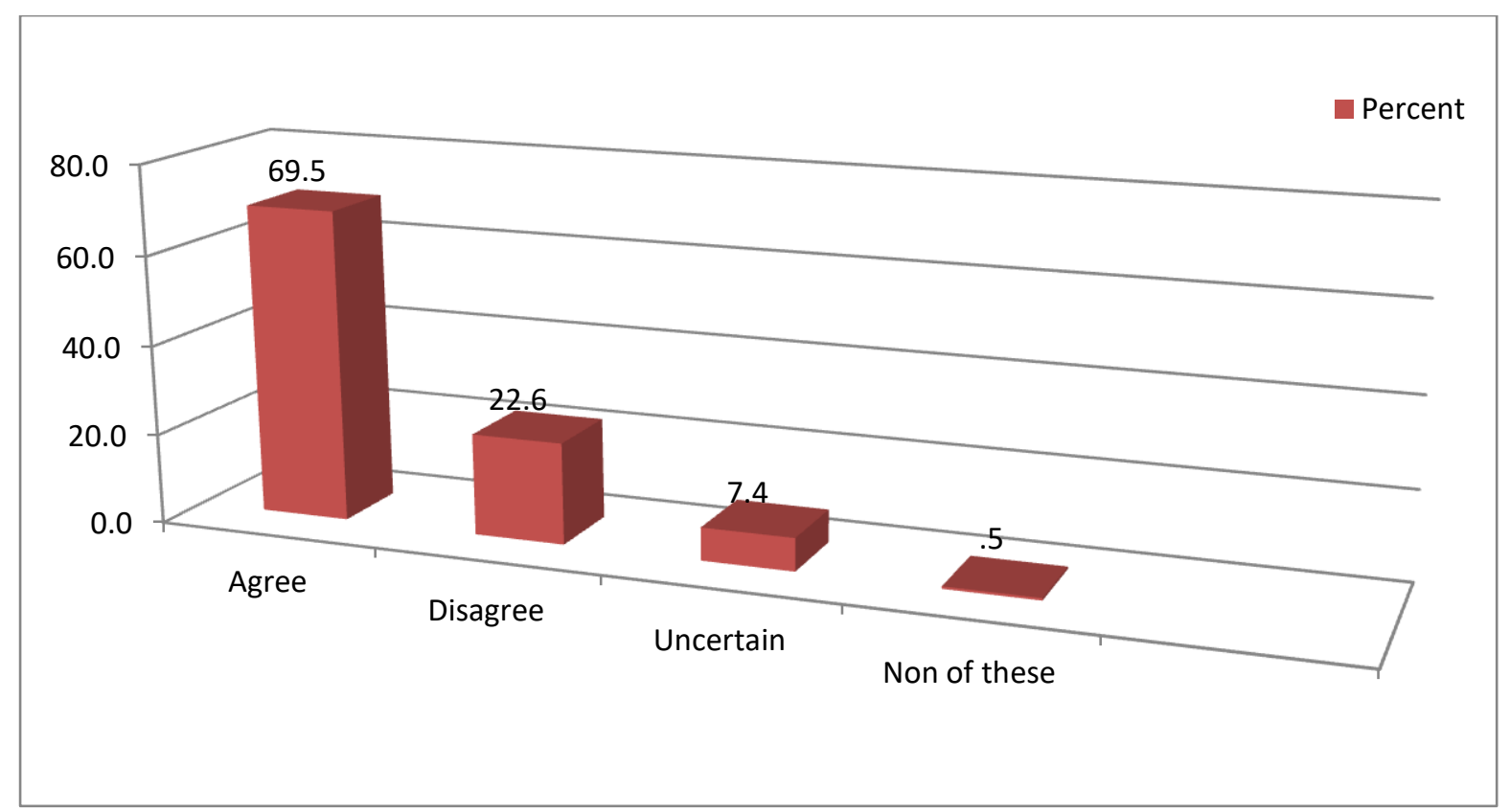

Figure 2: GB is associated with the Kashmir dispute

Source: Designed by the author based on data collection

\section{Hurdles in Constitutional Status}

In the light of the view of respondents about the primary hurdle in the constitutional status of GB, the primary hurdle in the CSGB is the Kashmir dispute, $52.6 \%$ of the respondent are agreed with the statement that the unresolved Kashmir dispute is the key hurdle in the CSGB as (Siddiqa, 2017) finds in her study. On the other hand, $44.7 \%$ of respondents did not consider the Kashmir issue a primary hurdle in constitutional status. Furthermore, in the FGD, participants are also articulated that the Kashmir dispute is a primary hurdle in getting constitutional status to Gilgit Baltistan, as (Flowerday, 2019) specified in his study.

\section{Political leaders of GB and people perceptions}

The majority of the respondents think that the current political leaders of GB are not enough to solve the issue of CS. The below figure shows the public perception regarding the political leaders of GB. About 70.5 percent of respondents' opinion is that GB's present political leaders are not enough to resolve the issue of constitutional status. Although the FGD participants' views are different but one thing in common about the current political leaders of GB that "political leaders from GB are associated with the major political parties of the mainland like PTI, PPP, PMLN, and many more. That's why the political leader of GB has no role in their party policy-making and there have not enough power to raise their voice on the party level."

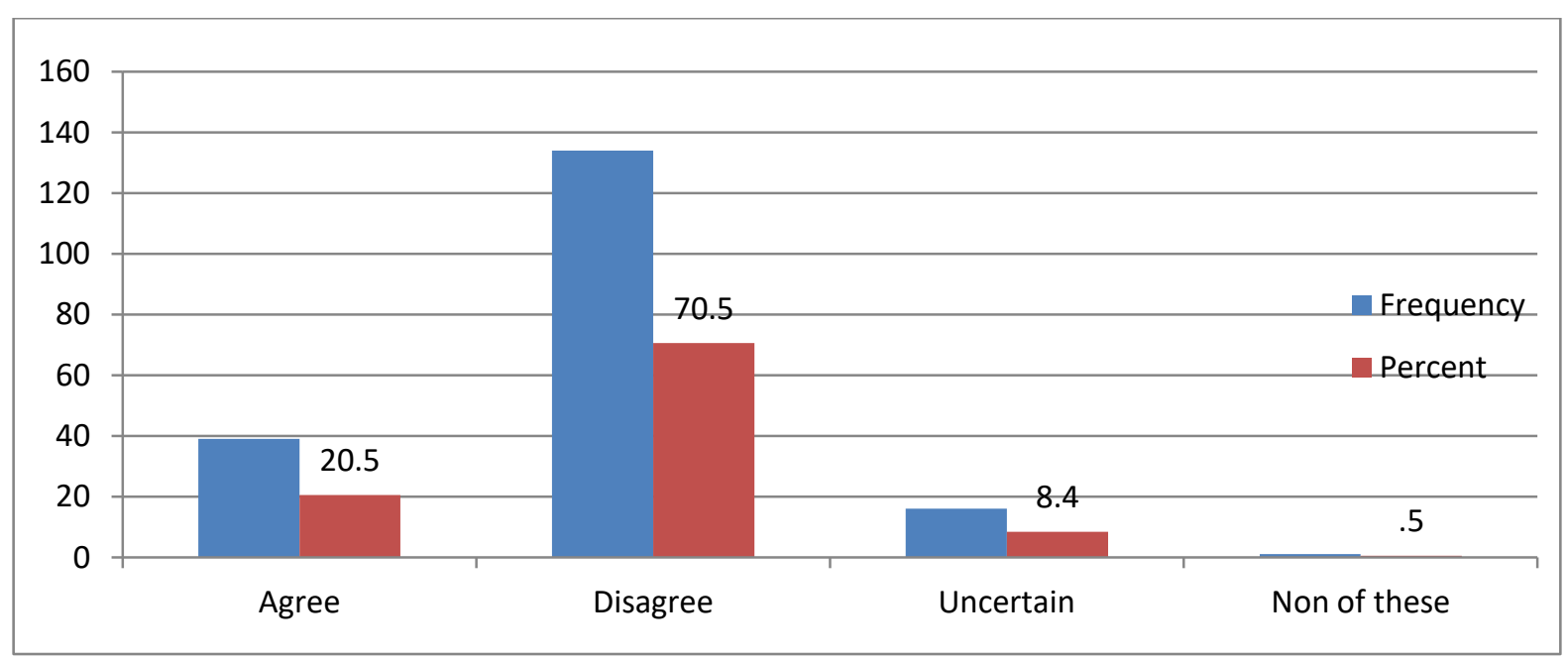

Figure 3: Current political leaders of GB is enough to resolve the issue of CS

Source: Designed by the author based on data collection 


\section{The desire of the Nationalist party}

In FGD, the majority of participants are in favor of the formation of a nationalist party to resolve the constitutional problem, but they had huge concerns about the reaction of the federal government and their agencies. One of the participants said that the nationalist of GB is treated as an alien and enlisted schedule four as well as ECL (exit control list). The 127 respondents are agreed with the statement that "GB needs a nationalist party to resolve the constitutional status," as (Hong, 2012) stated in his study, but 44 respondents disagreed with the statement while 15 respondent responses were uncertain, and 4 respondents were not aware of the statement. The below table shows the analysis of obtained data.

Table 1: GB needs a nationalist party to resolve the issue of CS

\begin{tabular}{lll}
\hline & Frequency & Percent \\
\hline Agree & 127 & 66.8 \\
\hline Disagree & 44 & 23.2 \\
\hline Uncertain & 15 & 7.9 \\
\hline None of these & 4 & 2.1 \\
\hline Total & 190 & 100.0 \\
\hline
\end{tabular}

Source: Drawn by the author based on collected data

\section{The primary demand of youth}

The following table shows public perceptions about the primary demand of GB's youth, and 48.4 percent of respondents are in favor of constitutional status. As Khan, 2020 find out in his research, 28.4 percent respondent wants full-fledged provincial setup and 18.9 percent respondents primary demand is Azad Kashmir like setup while 4.2 percent response is none of these. Participants of FGD articulated that if GB got constitutional status, then the remaining issue like fullfledged province and provincial autonomy will automatically solve because elected leaders from GB can raise their issues in National Assembly for legislation.

Table 2: The primary demand of GB youth

\begin{tabular}{lcccc}
\hline & Frequency & Percent & Valid Percent & Cumulative Percent \\
\hline constitutional status & 92 & 48.4 & 48.4 & 48.4 \\
\hline Azad Kashmir like setup & 36 & 18.9 & 18.9 & 67.4 \\
\hline full fledge setup & 54 & 28.4 & 28.4 & 95.8 \\
\hline none of these & 8 & 4.2 & 4.2 & 100.0 \\
\hline Total & 190 & 100.0 & 100.0 & \\
\hline
\end{tabular}

Source: Drawn by the author based on collected data

\section{Undefined constitutional status and public response}

The below table shows the respondent's perception of the undefined constitutional status of GB. Among 190 respondents only 11.6 percent are happy with the current status while 80 percent respondent is unhappy with the current status of GB. In FGD, participants argued that peoples of GB need more attention and privileges than constitutional status because they are not able to pay direct taxes, while Ali Muhammad, a Ph.D. scholar, argued that constitutional status has more importance than taxes (Flowerday, 2019) and (Jalal, 1995) concluded in his study. Due to ambiguous constitutional status, Gbians (peoples of GB) are neither Pakistani nor Kashmiri.

Table 3: As a graduate/student, are you happy with the undefined status of GB

\begin{tabular}{lcccc}
\hline & Frequency & Percent & Valid Percent & Cumulative Percent \\
\hline Agree & 22 & 11.6 & 11.6 & 11.6 \\
\hline Disagree & 152 & 80.0 & 80.0 & 91.6 \\
\hline Uncertain & 11 & 5.8 & 5.8 & 97.4 \\
\hline None of these & 5 & 2.6 & 2.6 & 100.0 \\
\hline Total & 190 & 100.0 & 100.0 & \\
\hline
\end{tabular}

Source: Drawn by the author on the basis of collected data

\section{Local leaders and constitutional status}

Respondent's perception about the local leaders of GB showed in the below table. 76.3 percent of respondents agreed that local leaders are not faithful to solve the issue of constitutional status as Bodla, 2014 articulated in his research, and only 15.8 percent disagreed with the statement, while 7.4 percent of respondents are unclear about the statement. The participants of FGD argued that the local leaders are associated with the mainland parties (PPP, PMLN, PTI, MWM, MQMP, and many more), and leaders from GB have to obey the party's policies. Owing to a limited role in mainland 
politics as well as non-membership in the upper and lower house, federal political parties are not interested in solving the issue of constitutional status as Zain, 2010 finds out in his study.

Table 4: Local leaders are not faithful to solve the issue of the constitutional status of GB

\begin{tabular}{lcccc}
\hline & Frequency & Percent & Valid Percent & Cumulative Percent \\
\hline Agree & 145 & 76.3 & 76.3 & 76.3 \\
\hline Disagree & 30 & 15.8 & 15.8 & 92.1 \\
\hline Uncertain & 14 & 7.4 & 7.4 & 99.5 \\
\hline None of these & 1 & .5 & .5 & 100.0 \\
\hline Total & 190 & 100.0 & 100.0 & \\
\hline
\end{tabular}

Source: Drawn by the author based on collected data

\section{Role of Kashmiri leaders}

The role Azad Kashmiri leaders are one the most important element regarding the issue of the constitutional status of GB and the respondent perceptions shows the hypothesis is accurate. $75.3 \%$ of the respondent agreed with the statement that leaders from Azad Kashmir are not in favor of solving the constitutional status of Gilgit Baltistan (CSGB) Ali \& Akhunzada, 2015 examine in his investigation. However, 14.2 percent of the respondents disagreed with the statement while 9.5 percent of the respondent were unclear about the statement, and only 1.1 percent answer was none of these. The below table shows the detail of the quantitative approach. The FGD concluded that Kashmiri leaders are against the annex of the GB in Pakistan. They consider GB as a part of the princely state of Maharaja, same as the verdict of the Supreme Court of Azad Jammu and Kashmir on September 14, 1994, and the findings were examined (Haque, 2012). Hence the future of GB will be decided with the solution of the Kashmir dispute.

Table 5: Leaders from Azad Kashmir are not in favor to solve the constitutional issue of GB

\begin{tabular}{lcccc}
\hline & Frequency & Percent & Valid Percent & Cumulative Percent \\
\hline Agree & 143 & 75.3 & 75.3 & 75.3 \\
\hline Disagree & 27 & 14.2 & 14.2 & 89.5 \\
\hline Uncertain & 18 & 9.5 & 9.5 & 98.9 \\
\hline None of these & 2 & 1.1 & 1.1 & 100.0 \\
\hline Total & 190 & 100.0 & 100.0 & \\
\hline
\end{tabular}

Source: Drawn by the author based on collected data

\section{Political System and the Legislative Setup}

The below table shows the public perceptions about the current political system and legislative setup (GBLA), and only $16.3 \%$ of the respondent is agreed with the statement that "the current political system and legislative setup is enough to solve the issue of CSGB" as Hussain, (2009) mention in his manuscript but 69.5 percent disagreed with the statement. It means GB needs something different than the current political and legislative setup. The FGD participants reasoned that the legislative setup is powerless, and major decisions are taken by bureaucrats, then political leaders, and the legislative assembly. They also claimed that Legislative Assembly has less power than the Ministry of Kashmir Affairs and Gilgit Baltistan (MKAGB), similar to the study of (Bouzas, 2013) and people of GB can't vote for the selection of the minister of MKAGB. One of the participants argued that "ministers for Kashmir and GB are appointing by the federal government, and they have to obey that particular person."

Table 6: The Current political system and legislative setup is enough to solve the issue

\begin{tabular}{lcccc}
\hline & Frequency & Percent & Valid Percent & Cumulative Percent \\
\hline Agree & 31 & 16.3 & 16.3 & 16.3 \\
\hline Disagree & 132 & 69.5 & 69.5 & 85.8 \\
\hline Uncertain & 26 & 13.7 & 13.7 & 99.5 \\
\hline None of these & 1 & .5 & .5 & 100.0 \\
\hline Total & 190 & 100.0 & 100.0 & \\
\hline
\end{tabular}

Source: Drawn by the author based on collected data

\section{Emerging Nationalist Sentiments and GBCS}

The following figure shows the respondents' views about the emerging nationalist sentiments, and 52.6 percent of respondents agreed that the emerging nationalist sentiments could help to solve the issue of CSGB, and 28.4 percent disagreed with the statement. However, 16.8 percent of the respondents are not clear about the question, and 2.1 percent answer is none of these. The FGD also concluded that the emerging nationalist sentiments are helpful to solve the myth of CSGB and requested for the peaceful resolution of the issue as similar to (Bodla's, 2014) finding in his manuscript. 


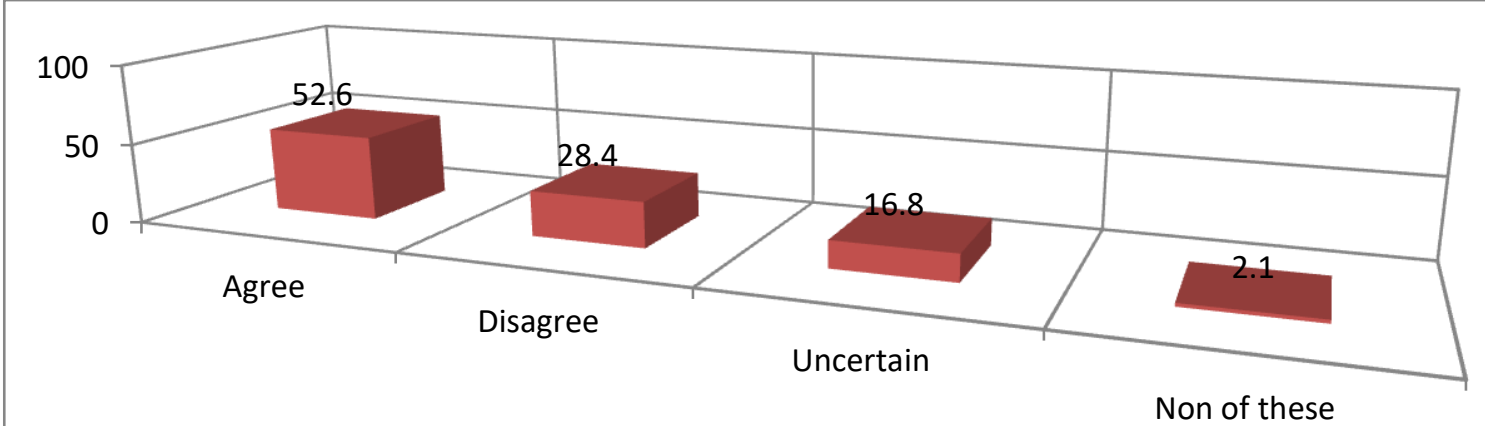

Figure 4: Emerging nationalist sentiments in GB can help to solve the issue of CSGB

Source: Design by the author based on collected data

\section{Undefined Constitutional Status and Nationalist Sentiments}

The following table shows the people's perception about the major contributor in creating nationalist sentiments in Gilgit Baltistan, and 66.8 percent of respondents agreed with the statement. It shows that unclear constitutional status is the major contributor in creating nationalist sentiment among youth, particularly among university students because the whole respondents are university students or graduates. The 20 percent respondent disagrees with the question, and 12.6 percent of the respondent is not clear about the statement, while only 0.5 percent thinks something different. The focus group participants argued that the in-between constitutional status youth, especially university students, feel alienation and anxiety lead towards the sub-nationalism path, and a parallel opinion is stated in (Hunzai, 2013).

Table 7: The undefined constitutional status is the major contributor in creating nationalist sentiments in GB

\begin{tabular}{lcccc}
\hline & Frequency & Percent & Valid Percent & Cumulative Percent \\
\hline Agree & 127 & 66.8 & 66.8 & 66.8 \\
\hline Disagree & 38 & 20.0 & 20.0 & 86.8 \\
\hline Uncertain & 24 & 12.6 & 12.6 & 99.5 \\
\hline None of these & 1 & .5 & .5 & 100.0 \\
\hline Total & 190 & 100.0 & 100.0 & \\
\hline
\end{tabular}

Source: Drawn by the author based on collected data

\section{CPEC and CSGB}

The following figure shows respondents' responses to the question that "China Pakistan Economic Corridor" (CPEC) can help determine the CSGB. The figure shows that $53.7 \%$ of respondents agreed, and similar findings were articulated in Asif \& Ling, 2019 and Shafique, 2017. But 31.6 percent disagreed while 13.7 percent of respondents are not clear about it as well as 1.1 percent of respondents answer is none of these. The FGD also concluded that CPEC could play a vital role in defining GB status, but there is fear among locals that owing to massive transportation and mega projects, the demography of GB is facing a severe threat as like the conclusion of (Wolf, 2016) in his manuscript.

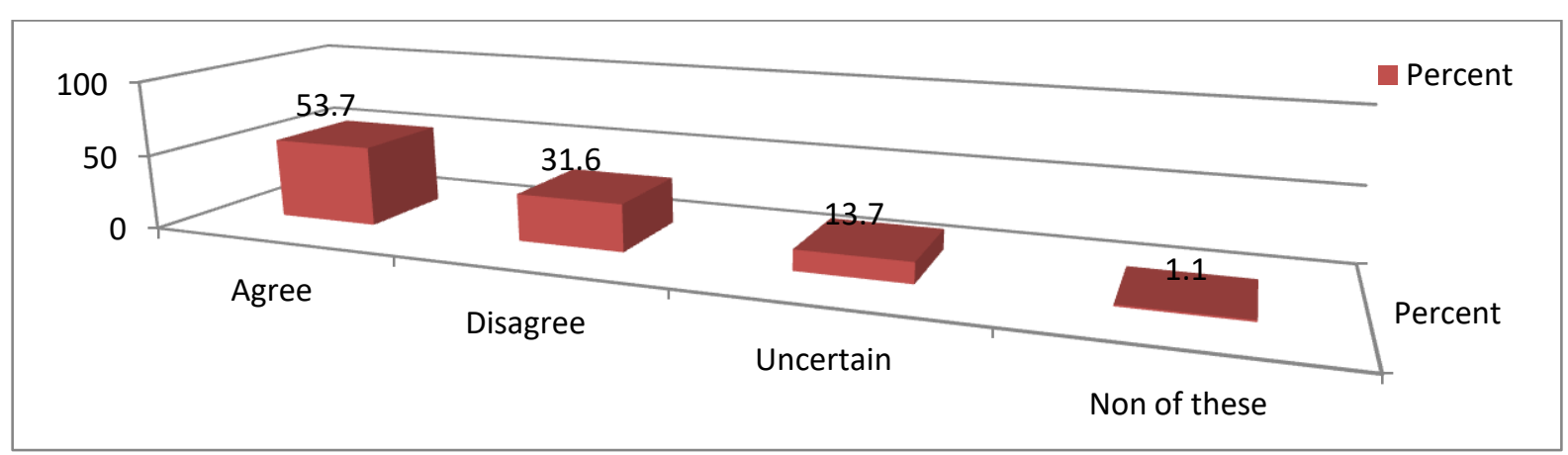

Figure 5: CPEC can help to determine the constitutional status of GB

Source: Design by the author based on collected data

\section{Full Fledge Province}

The following figure shows the public response to the statement "GB as a full-fledge province as India did in occupied Kashmir." 55.8 percent of respondents agreed with the statement, and 30.5 disagreed with the statement. On the other hand, 11.6 percent are unclear about the statement, and 2.1 percent response is none of these. However, the participant of FGD articulated that Pakistan has to declare GB as the full-fledged province of Pakistan. The demand for a full-fledge 
province with autonomy under the $18^{\text {th }}$ amendment is the unified conclusion of FGD, but on March 09, 2021, GBLA adopted the joint resolution unanimously regarding the constitutional status of GB. The " federal government, prime minister and other states institution are demanded to amend the constitution for GB's interim provincial status without damaging the Islamabad's stance on Kashmir"(Nagri, 2021).

Table 8: GB as a full-fledge province as India did in occupied Kashmir

\begin{tabular}{lcccc}
\hline & Frequency & Percent & Valid Percent & Cumulative Percent \\
\hline Agree & 106 & 55.8 & 55.8 & 55.8 \\
\hline Disagree & 58 & 30.5 & 30.5 & 86.3 \\
\hline Uncertain & 22 & 11.6 & 11.6 & 97.9 \\
\hline None of these & 4 & 2.1 & 2.1 & 100.0 \\
\hline Total & 190 & 100.0 & 100.0 & \\
\hline
\end{tabular}

Source: Drawn by the author based on collected data

\section{Diamer-Basha Dam and CSGB}

The site of the mega-project Diamer-Basha dam sited in the territory of GB, and the following table shows public perception about the project's significance for solving CSGB. The following table shows the respondent's response to the question "Diamer-Basha dam can help determine the CSGB," only 37.9 percent of respondents agreed, but 41.1 percent of respondents disagreed with the statement. However, 20 percent response is ambiguous, and 1.1 percent response is none of these. The participants of FGD are also not hopeful about the role of the mega project in solving CSGB, as (Jabeen \& Bukhari, 2020) concluded in their analysis.

Table 9: Diamer-Basha dam can help to determine the CSGB

\begin{tabular}{lcccc}
\hline & Frequency & Percent & Valid Percent & Cumulative Percent \\
\hline Agree & 72 & 37.9 & 37.9 & 37.9 \\
\hline Disagree & 78 & 41.1 & 41.1 & 78.9 \\
\hline Uncertain & 38 & 20.0 & 20.0 & 98.9 \\
\hline None of these & 2 & 1.1 & 1.1 & 100.0 \\
\hline Total & 190 & 100.0 & 100.0 & \\
\hline
\end{tabular}

Source: Drawn by the author based on collected data

\section{Discrimination and CSGB}

The following figure shows the respondent's response to the question "being a university student/ graduate faced any problem and discrimination due to ambiguous CSGB." The figure shows that 74.7 percent of a student of Gilgit Baltistan are faced problems and discriminations due to the issue of ambiguous constitutional status as (Flowerday, 2019) and (Bansal, 2018) articulated in his study that identity matters. The whole respondents are university students and graduates from Gilgit Baltistan, and only 15.8 percent disagreed with the statement. It shows the students of GB are facing discrimination and problems due to in-between status. The participants of FGD point out several problems and discrimination that participants faced. The discussion concluded that students of GB are not able to apply for admissions in several universities of Pakistan. However, there are few reserve seats in universities that is not enough. There are only two universities in GB with limited departments and miserable infrastructure. However, there is neither a single medical and technical college nor any engineering institute in the whole region; despite all harsh realities, now the region hostiles capital territory in the education sector.

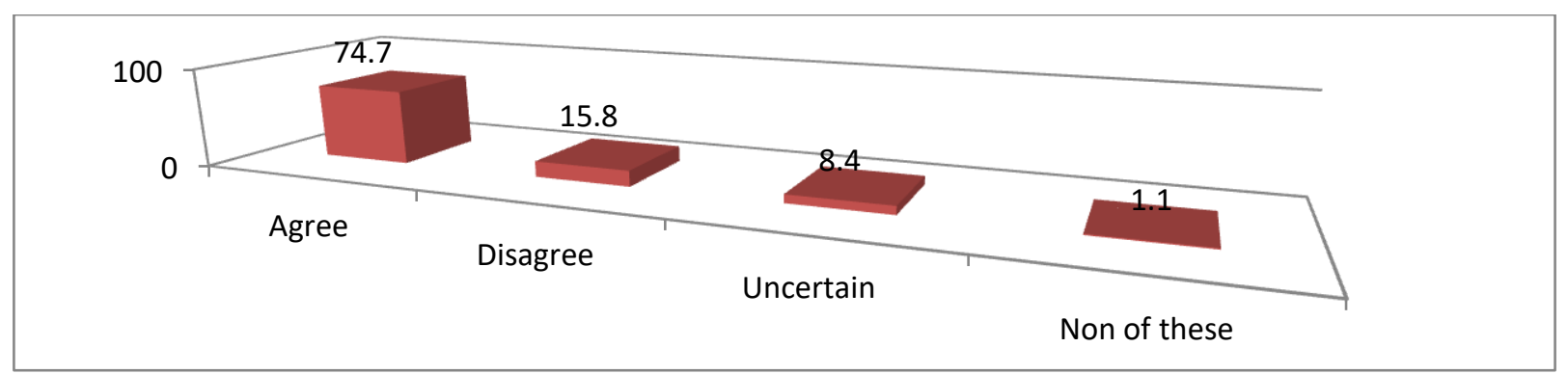

Figure 6: Being a University student face any problem and discrimination due to ambiguous constitutional status of GB

Source: Design by the author based on collected data

\section{DISCUSSION}

The university students and graduates from GB provided their perception towards the myth of the constitutional status of Gilgit Baltistan by participating in the survey and focus group discussion. The graduates and university students are 
considered the backbone of society, and they play a key and vital role in shaping the future of their place of origin. The graduated and university students of Gilgit Baltistan are studying in different cities of Pakistan. The number of students in the universities outside the Gilgit Baltistan region is more than the students who are studying in the only two existing universities of the region. The students outside the region become more concerned and apprehend regarding the region's constitutional status and future political affiliation. The participants showed their perception on three different themes; first, primary hurdles in determining and delaying Constitutional Status of Gilgit Baltistan (CSGB); second, fears and ambiguity among youth owing to the issue of constitutional status; and third, demand and desire of GB youth regarding the constitutional status.

A few decades back, the only desire and demand of the people of the Gilgit Baltistan region, including all the stakeholders along with the youth, was affiliation with Pakistan in a constitutional way, but with the passage of time, the youth of the region are expressing their reservation and stipulation regarding affiliation with Pakistan under current conditions and circumstances. Results show that the youth of Gilgit Baltistan are considering the Kashmir issue as a key hurdle in determining the constitutional status of GB. As 69.5 percent of respondents consider that GB is associated with Kashmir dispute and participants response shows that the primary hurdle in determining CSGB is the Kashmir dispute, same as (Sering, 2010) and (Flowerday, 2019) articulated their research. GB is associated with the Kashmir dispute between India and Pakistan. According to the youth, the political statements of top Kashmiri leaders for the constitutional development and constitutional advancement of the GB region are discouraging and disappointing. The youth of GB considers that there is no association of Kashmir dispute with the political future of GB as Gilgit Baltistan region got independence on their resource without any external help. The participants' response also determined the factor that delaying resolving the CSGB is the lack of political leaders.

The undefined CS of GB creates fears and ambiguity among the youth of GB, particularly in university students and graduates. Many opportunities for the region and the youth are limited just because of ambiguous status in the constitution. The participants of FGD concluded that owing to the less job opportunities and limited quota in federal organization increasing ambiguity day by day as regarding the literacy rate couples of districts of the Gilgit Baltistan region compete with the major cities of the country with top ten positions. The graduates and university students prefer to serve in the region after completing the degree, but they can get private teaching opportunities and nothing else after returning to the region. The local government of GB is dependent on the Federal government for the creation and announcement of posts. After creating the post, the conduction of tests and interviews for the advertised posts also rely on the Federal's private testing services and Public service commission due to no such setup in the whole region. The key contributor of fears and ambiguity is the undefined constitutional status as literature postulated (Dad, 2016), (Flowerday, 2019), and (Lambah, 2016).

The results show that the people of Gilgit Baltistan face discrimination in all fields of life due to their constitutional status. All the key administrative posts in almost all the departments of the GB region are currently being served by the non local officers and personnel due to a discouraging level of representation to the degree holders of GB in job allocation. It is also diverging the minds of youth towards sub-nationalism, as (Bolda, 2014) find out in his study.

The participants are pessimist about the role of megaproject Diamer-Basha Dame and CPEC in determining their constitutional status, especially the CPEC, as the GB region is the gateway (the starting point) of this mega project. The ambiguous status of the constitution for the region is harmful to both the region and CPEC. To ensure the maximum credibility of the project, the provision of constitutional status to the GB region is inevitable. The participants have reservations regarding GB's zero roles in CPEC policy-making as (Asif \& Ling, 2019) articulated in their study.

The demand and desire of the people of Gilgit Baltistan is the full fledge province with full autonomy and authority as the current government and assembly in the Gilgit Baltistan region mainly implement the decisions of the Federal government in the so-called provincial setup. The main authorities, including allocation of budget, dealing of tourism, external affairs, and many other works, are directly controlled by the Prime Minister, Federal Ministers, and even by the secretaries of Kashmir and GB affairs. Despite tourism hub and great opportunities for tourism, all the policies and strategies regarding tourism are dealt with in Federal including the revenue. The inferiority among the youth of GB, especially among the graduates regarding the region's constitutional status and political future, is increasing day by day. The participants of FGD demanded full constitutional status with membership in the upper and lower house and due share in NFC Award, CPEC, and Diamer-Basha Dam.

The representation in Senate and Parliament as an observer, which is under consideration in the capital city, is rejected by the graduates and university students of the region. Any such attempt can escalate and raise the concerns and reservations in the region. The representation in both the Houses is acceptable for the youth of the region under complete constitutional way. The 69.5 percent of the respondents are not happy with the current legislative setup as the current setup didn't help the development and advancement of the constitutional setup. The present setup is a province-like setup, not a provincial setup. The recent ruling of GBLA, which passed unanimously on March 09, 2021, shows the demand and desire of the public regarding the myth of constitutional status (Nagri, 2021). The participants also demanded to recognized GB as a fifth constitutional province in response to the article $35 \mathrm{~A}$ and 370 of the Indian constitution. 


\section{CONCLUSION}

The people of Gilgit-Baltistan are suffering since day one due to ambiguous constitutional status. Owing to the unclear constitutional status, they are neither a full Pakistani citizen nor Kashmiri. This study finds out that the primary hurdle in determining and delaying the constitutional status of Gilgit Baltistan is its historical facts, Kashmir dispute, leadership crisis in GB, undesirable role of Kashmiri leader, and the non-serious behavior of Islamabad and its institution.

The youth of GB are facing ambiguity and anxiety owing to the ambiguous status that tilts their mind towards subnationalism and GB's first policy. The in-between status also creates a missing trust and misperception between state and citizen that's why several activists and nationalists are imposed ATA (Anti-Terrorism Act) and on the exit control list (ECL). Owing to the limbo of constitutional status, nationalist sentiments are increasing day by day, but they want peaceful and political solutions to the problem.

Further, the study finds out that the peoples are in doubt regarding the impacts of the Diamer-Basha Dam in determining the status of Gilgit Baltistan. Furthermore, the game-changer CPEC creates uncertainty and insecurity among youth owing to no representation from GB in CPEC regarding meetings and visits. Although the mega project has few projects for GB, it will destroy the demography as well as the flora and fauna of the region. Moreover, the in-between position of GB creates discrimination and troubles for her inhabitants. That's why the people of Gilgit-Baltistan are persecuted for living with ambiguity and guilt. The study also finds out that the people, particularly the youth of GB, are not cheerful with the unclear constitutional status and the desire and the demand of youth is Azad Kashmir-like set up with full internal autonomy. The current political setup does not help determine ambiguous status; that's why they favor full recognition with full provincial autonomy under the $18^{\text {th }}$ amendment and due seats in the upper and lower house of Islamabad and due share in NFC award and CCI. While according to the current situation under the shadow of the Supreme Court of Pakistan verdict of 2019 and the GBLA ruling of March 09, 2021, the limbo of constitutional status is pessimistic. However, if Islamabad fulfills the demand of the GBLA ruling of March 09, 2021, that would be old wine in a new bottle.

\section{RECOMMENDATIONS}

It is the perfect time to resolve the constitutional issue of GB as India did in occupied Kashmir. India declared occupied Kashmir as a constitutional part of India, but the Pakistani government is not showing flexibility to resolve the issue of the constitutional status of Gilgit Baltistan. The future of Gilgit Baltistan's constitutional status is pessimistic in the current scenario of international politics because the role of the United Nations in solving the Kashmir dispute is feeble. According to the Supreme Court of Pakistan's verdict of January 2019, the future of Gilgit Baltistan will not decide until the solution of the Kashmir dispute.

The government of Pakistan has to pass new legislations about GB, and the region should be established province by ignoring the link of the region with the Kashmir issue. GB must have representation in National Assembly and Senate as similar to other provinces. The GB Legislative Assembly must be renamed as Provisional Assembly of GB with full power like other provisional assemblies. The federal minister for GB should be elected from GB either by direct election or by indirect election.

The government of Pakistan should establish proper educational institutions for higher studies in GB, especially engineering and medical college. The royalty of the Indus River, $\mathrm{K} 2$ peak, $\mathrm{KKH}$, and other sites should grant to the GB provisional government. Government should boost up the Tourism sector in GB that will create job opportunities, and it will help minimize the sub-nationalism sentiments among youth.

\section{LIMITATIONS OF THE STUDY}

The study is fundamentally limited to the constitutional status of Gilgit Baltistan and the public perception, particularly youth perception towards constitutional limbo.

\section{IMPLICATION OF THE STUDY}

This study provides a bundle of information about the constitutional status of GB for all readers and provides a guideline for new researchers. The research will help policymakers to resolve the myth, and it also contributes some recommendations.

\section{ACKNOWLEDGEMENT}

No financial support is engaged, and the research is completed with researchers' resources.

\section{AUTHORS CONTRIBUTION}

Najaf Ali has devised the main idea and wrote the paper. Mian Muhammad Azhar has Developed a research design and analyzed the data. Shakil Akhtar contributed to collecting the data. Sarfraz Batool has contributed to drawing Graphs. Sidra Akram has done the proofreading. 


\section{REFERENCES}

1. Ali, N. (2019). Delusional States. Cambridge University Press. https://doi.org/10.1017/9781108609166

2. Ali, S. W., \& Akhunzada, T. (2015). Unheard voices: engaging youth of Gilgit Baltistan. London, UK: Conciliation Resources.

3. Asif, M., \& Ling, Y. B. (2019). China Pakistan Economic Corridor (CPEC): International Media Reporting and Legal Validity of Gilgit-Baltistan. Asian Social Science, 15(2), 177-187. https://doi.org/10.5539/ass.v15n2p177

4. Bangash, Y. K. (2010). Three Forgotten Accessions: Gilgit, Hunza, and Nagar. The Journal of Imperial and Commonwealth History, 38(1), 117-143. https://doi.org/10.1080/03086530903538269

5. Bansal, A. (2018). Gilgit-Baltistan and its Saga of Unending Human Rights Violation. New Delhi: Pentagon Press.

6. Best, S. (2014). Understanding and doing successful research: Data collection and analysis for the social sciences. Routledge. https://doi.org/10.4324/9781315833545

7. Bodla, S. (2014). Making a nation in high mountains: Balawars and Balawaristan nationalism in Ghizer district of Gilgit Baltistan. 16.1. EthnoScripts: Zeitschrift für aktuelle ethnologische Studien, 16(1), 125-139.

8. Bouzas, A. (2013). Securitization and Development as Modes of Peripheralization in North-Eastern Pakistan. In Peripheralization, 77-98. Springer. https://doi.org/10.1007/978-3-531-19018-1_4

9. Bouzas, A. M. (2012). Mixed Legacies in Contested Borderlands: Skardu and the Kashmir Dispute. Geopolitics, 17(4), 667-886. https://doi.org/10.1080/14650045.2012.660577

10. Bouzas, A. M. (2017). Territorialization, Ambivalence, and Representational Spaces in Gilgit-Baltistan. The Journal of Transcultural Studies, 8(1), 197-223.

11. Dad, A. A. (2016). Boundaries and Identities: The Case of Gilgit-Baltistan. The crossroads Asia Working Paper Series, 34.

12. Dilshad, R. M., \& Latif, M. I. (2013). Focus Group Interview as a Tool for Qualitative Research: An Analysis. Pakistan Journal of Social Sciences, 33(1), 191-198.

13. Feyyaz, M. (2019). Geopolitics, statehood, violence and space compression in Gilgit-Baltistan. South Asian History and Culture, 10(1), 28-45. https://doi.org/10.1080/19472498.2019.1576297

14. Flowerday, J. (2019). Identity matters: Hunza and the hidden text of Britain and China. South Asian History and Culture, 10(1), 46-63. https://doi.org/10.1080/19472498.2019.1576299

15. Haque, I. u. (2012). Determining the Political Status Of Gilgit Baltistan Future Perspective. Islamabad: National University of Modern Languages.

16. Holden, L. (2019). Law, governance, and culture in Gilgit-Baltistan: introduction. South Asian History and Culture. 10(1), 1-13, https://doi.org/10.1080/19472498.2019.1576300

17. Hong, C. (2012). Liminality and resistance in Gilgit-Baltistan. Centre for International Sustainable Development Law (CISDL): Montreal, Canada.

18. Howe, K., \& Hunzai, I. (2019). The politics of exclusion. South Asian History and Culture, 10(1), 14-27. https://doi.org/10.1080/19472498.2019.1576298

19. Hunzai, I. (2013). Conflict Dynamics in Gilgit Baltistan. Washington: United States Institute of Peace.

20. Hussain, A. (2009). The Gilgit-Baltistan Reforms 2009. The Forum of Federations project in Pakistan-German Ministry of Foreign Affairs.

21. Hussain, Z., \& Javaid, U. (2018). Situating Gilgit-Baltistan in growing China Pakistan Interdependence: Post 9/11 Scenario. Journal of Political Studies, 25(2), 291-310.

22. Jabeen, S., \& Bukhari, M. H. (2020). Gilgit-Baltistan A Gateway in China Pakistan Relations: An Overview of Constitutional, Political, Strategic and Economic Dimensions. Pakistan Vision, 21(1), 14-34.

23. Jalal, A. (1995). Conjuring Pakistan: History as official imagining. International Journal of Middle East Studies, 27(1), 273-89. https://doi.org/10.1017/S0020743800061596

24. Joshi, P. (2019). Supreme Court ruling on Gilgit Baltistan: A legacy of unfulfilled promises. National Security, 2(1).

25. Khan, A. W. (2020). From subjugation to extinction a tragic history of the indigenous people of GilgitBaltistan. Fourth World Journal, 19(2), 8-24.

26. Khan, E. M. (2017). Constitutional Status of Gilgit-Baltistan: An Issue of Human Security. Margalla Papers, 2l(1), 85-103.

27. Khan, E. M. (2017a). The Role of Geography in Human Security: A Case Study of Gilgit-Baltistan. Margalla Papers.

28. Khan, I. S. (2015). The flow of history of governance in Gilgit Baltistan. Habib University, Karachi.

29. Kreutzmann, H. (2015). Boundaries and space in Gilgit-Baltistan. Contemporary South Asia, 23(3), 276-291. https://doi.org/10.1080/09584935.2015.1040733

30. Lambah, S. K. (2016). The Tragic History of Gilgit-Baltistan since 1947. Indian Foreign Affairs Journal, 11(3), 227.

31. Nagri, J. (2021, March 09). GB Assembly unanimously adopts joint resolution demanding interim provincial status. Retrieved March 12, 2021, from Daily Dawn: https://www.dawn.com/news/1611556/gb-assemblyunanimously-adopts-joint-resolution-demanding-interim-provincial-status 
32. Naseem, M. Q. (2007). Gilgit Baltistan Aur Masla-E-Kashmir. Skardu: Sang-e-meel.

33. Nayak, J. K., \& Singh, P. (2015). Fundamentals of Research Methodology Problems and Prospects (1st ed.). New Delhi, India: SSDN Publishers \& Distributors.

34. Pandey, D. P., \& Pandey, D. M. (2015). Research Methodology: Tools and Techniques (1 ed.). Buzau, Romania, European Union: Bridge Center.

35. Reportar, S. (2020, August 05). Pakistan affirms the claim to IHK with a new map. Retrieved March 10, 2021, from Daily Dawn: https://www.dawn.com/news/1572694

36. Saini, S., \& Dar, D. S. (2013). Geopolitical Significance of Gilgit Baltistan of J \& K State. International Journal of Humanities and Social Science Invention, 2(5), 48-56.

37. Sering, S. H. (2010). Constitutional Impasse in Gilgit-Baltistan (Jammu and Kashmir): The Fallout. Strategic Analysis, 34(3), 354-358. https://doi.org/10.1080/09700161003658998

38. Shafique, M., \& Iftikhar, G. A. (2017). Regional Dynamics of China Pakistan Economic Corridor (CPEC): The Case of Gilgit Baltistan. Journal of Historical Studies, 3(II), 15-29.

39. Shamsi, D. S., Mustafa, D. G., \& Ali, N. (2019). Pak-China Relations in 21st Century: a Critical Appraisal. Orient Research Journal of Social Sciences, 4(1), 107-121.

40. Shekhawat, S. (2011, January 18). Sectarianism in Gilgit-Baltistan. South Asia Terrorism Portal, 20.

41. Siddiqa, A. (2017). Reforms in Gilgit-Baltistan. Strategic Studies, 37(1), 108-123.

42. Singh, P. (2013). Gilgit Baltistan: Hope and Despair. New Delhi, India: Institute for Defence Studies and Analyses.

43. Sokefeld, M. (2014). Sökefeld, Martin. "Anthropology of Gilgit-Baltistan: Introduction. EthnoScripts: Zeitschrift für aktuelle ethnologische Studien, 16(1), 9-29.

44. Tanvir, A. (2020, November 25). Gilgit Baltistan Elections and Looming Challenges for the PTI. Retrieved March 2021, 10, from South Asian Voices: https://southasianvoices.org/gilgit-baltistan-elections-and-loomingchallenges-for-the-pti/

45. Wolf, S. O. (2016). China-Pakistan Economic Corridor (CPEC) and its impact on Gilgit-Baltistan. South Asia Democratic Forum, 25. https://doi.org/10.1007/978-3-319-56747-1_6

46. Zain, O. F. (2010). A Socio-Political Study of Gilgit Baltistan Province. Pakistan Journal of Social Sciences, 3(1), 181-190. 